\title{
EDUCAÇÃO PROFISSIONAL NO BRASIL: HISTÓRICO
}

\author{
PROFESSIONAL EDUCATION IN BRAZIL: HISTORY
}

\author{
Lidiane Soares Wittaczik
}

SENAIsc-Jaraguá do Sul, E-mail: lidiane@ senai-sc.ind.br

\begin{abstract}
Resumo. Este artigo apresenta um panorama histórico da educação profissional, desde os períodos remotos da história até o surgimento de novas tecnologias no setor produtivo nas últimas décadas. Ao tratar da educação profissional no Brasil, o artigo mostra que a formação profissional é realizada por escolas dos setores público e privado e pelas agências do Sistema S, guardando íntima relação com os avanços tecnológicos. Com base na legislação educacional brasileira vigente e diante da responsabilidade das instituições de ensino, de gerar saberes coletivos e flexíveis, sintonizados com as novas bases e novas formas de organização produtiva, fundadas na produção e difusão de inovações de cunho tecnológico, aborda-se a educação por competência como uma metodologia adequada a educação profissional.
\end{abstract}

Palavras-chave: Educação Profissional; Educação por competência; Educação - História

Abstract. This article presents an overview history of professional education, from the remote periods of history until the emergence of new technologies in the productive sector in recent decades. When dealing with professional education in Brazil, the paper shows that the training is done by schools of public and private sectors and the agencies of the $S$ System, keeping close relationship with the technological advances. Based on the current Brazilian educational legislation and in the face of the responsibility of the teaching institutions, of producing collective and flexible knowledge, tuned with the new bases and forms of productive organization, founded on production and diffusion of technological innovations, education by competence is described as an adequate methodology for professional education.

Key words: Professional Education; Education by Competence; Education History

\section{EDUCAÇÃO PROFISSIONAL: HISTÓRICO}

O fenômeno da educação profissional acompanha as práticas humanas, desde os períodos mais remotos da história, quando os humanos, segundo Manfredi (2002), transferiam seus saberes profissionais por meio de uma educação baseada na observação, na prática e na repetição, pelas quais repassavam conhecimentos e técnicas de fabricação de utensílios, aprimoramento de ferramentas, instrumentos de caça, defesa e demais artefatos que lhes servissem e facilitassem o cotidiano. Com sua cognição e tecnologia acumuladas, as populações pré-históricas e as civilizações que as seguiram produziram soluções para enfrentarem os desafios impostos pelo ambiente no qual estavam inseridos, bem como nas 
suas relações e interferências com os demais componentes ambientais, como ainda nos atos civilizatórios e nos de conquista.

Manfredi (2002) esclarece que os humanos, ao longo dos tempos, valendo-se dos recursos de que dispunham nos diversos ambientes terrestres, desenvolviam artefatos com maestria, arte e praticidade, e os saberes eram repassados de geração para geração. Essa pedagogia pode ser comprovada, por exemplo, em peças de acervo museológico antrópico ${ }^{1}$, em que são demonstradas as diversas formas do trabalho humano que, segundo Manfredini (2002, p. 33), "[...] é uma atividade social central para garantir a sobrevivência de homens e mulheres e para a organização e o funcionamento das sociedades".

Por meio de um acervo, é possível atestar que havia relação estreita entre sujeito e objeto, homem e natureza, entre quem conhece e a realidade conhecida, características presentes em "economias primitivas de subsistência" (MANFREDI, 2002, p. 37). Essas sociedades, embora se valessem de meios e instrumentos rudimentares de produção, seguiam uma lógica que não era a da acumulação, ideologia presente na atual perspectiva do mercado, mas em experiência baseada na pedagogia de erro e acerto, de repetição de saberes acumulados pela história e cultura. Ainda de acordo com Manfredi (2002, p. 37), "[...] tais meios e instrumentos encontravam-se à disposição de todos e as técnicas eram dominadas por qualquer um que queria ter acesso a elas". A respeito do mesmo assunto, Jinkings (apud MÉSZÁROS, 2005, p. 9), esclarece que a pedagogia era de caráter reconstrutivo e utilitarista, uma educação "para a vida" e não para a "[...] lógica desumanizadora do capital, que tem no individualismo, no lucro e na competição seus fundamentos".

Atualmente, temos a Educação Profissional que se consolidou a partir da Revolução Industrial ocorrida na Inglaterra, em meados do final do século XVIII e início do século XX, ocasião em que, conforme a Enciclopédia de Diderot e D'Alembert (2006), pela primeira vez descreveu-se o quadro de ocupações da época, bem como, o que deveria ser estudado para o exercício das mesmas. Para Manfredi (2002), essa vinculação tardia entre educação e trabalho é compreensível, por conta das relações sociais específicas das sociedades Antiga e Medieval que se mantinham vinculadas a poderes centralizados, nos senhores feudais ou na igreja. De acordo com o mesmo autor, as noções de trabalho "[...] vão se construindo e reconstruindo ao longo da história das sociedades humanas, variando de acordo com os modos de organização da população e de distribuição de riqueza e poder" (p. 34). Em outras palavras, naquelas sociedades, as relações eram demarcadas por um divisor entre aqueles que eram os senhores da terra e da produção e do capital, dos cidadãos, os que viviam nas cidadelas e os que eram escravos, serventes. O poder era supostamente predestinado e o acesso ao conhecimento elaborado era privilégio das classes dominantes. No entanto, segundo Frigotto (1999), a modernidade alterou o vínculo entre trabalho produtivo e educação com o advento do capitalismo, em que a produção se rende ao mercado, o qual assume para si a organização da produção e suas relações de capital e trabalho. Ainda para o autor, o capitalismo determina as regras sobre valores, idéias, teorias, símbolos e instituições, entre as quais se destaca a escola como espaço de produção e reprodução de conhecimentos, atitudes, ideologias e teorias que justificam o novo modo de produção (FRIGOTO, 1999 apud SENAC, 2007). 
A partir da disseminação das escolas de Artes e Ofícios, as técnicas passaram a ser sistematicamente difundidas com o intuito de preparar gerações vindouras para a continuidade dos ofícios, especialmente no século XVIII, quando a Revolução Industrial inglesa promoveu profundas alterações nas relações de produção e capital e, conseqüentemente, nas estruturas e modelo de educação que deveria suprir o mercado produtivo, dominado pela burguesia emergente. Nessa direção, Manacorda (1995, p. 286), ao discorrer sobre as ciências aplicadas que se tornavam ensino mais regular e normal diz: "Escolas de agricultura, escolas de comércio, escolas de artes e ofícios, sociedades de estímulo em favor da indústria e das artes manuais, se instituem e se multiplicam [...]", demonstrando que a mão-de-obra precisava ser capaz de atender à demanda emergente, ou seja, de servir à maior produção de bens para o consumo. Entretanto, para muitos donos dos meios de produção da época, a escolarização operária se tornou um problema, pois muitos desses "patrões" entendiam que "[...] era supérfluo e até perigoso ensinar a ler, escrever e, especialmente, fazer contas aos operários [...]" (MANACORDA, 1995, p. 287), já que na visão deles, possivelmente, se os operários fossem instruídos, poderiam promover uma revolução, ou seja, poderiam exigir aquilo que lhes era devido: salário justo, salubridade dos postos de trabalho, carga de trabalho compatível com sua condição de humanos. Isto significa que se tornariam indivíduos esclarecidos, com lucidez e consciência de sua participação e sua função no mundo, sendo capazes de se avaliarem e refletirem a respeito de sua ação no mundo. Pela preocupação patronal apontada por Manacorda (1995), o trabalhador deveria ter, unicamente, noções técnicas, domínio de seu ofício e disposição para trabalhar, sem educação. Em outras palavras, o trabalhador não deveria ser detentor de conhecimentos que a ele possibilitassem entender que é possível promover o que Jinkings (apud MÉSZÁROS, 2005) denomina de "separação entre Homo faber e Homo sapiens" ou, então, que é possível se transformarem, conforme menciona Freire (2006), em reais sujeitos da construção e reconstrução do saber ensinado, e promoverem autonomia e libertação.

\section{A EDUCAÇÃO PROFISSIONAL NO BRASIL}

O contexto apresentado exerceu influência sobre a Educação Profissional no Brasil, que teve seu início oficial em 1909 e cuja trajetória histórica encontra-se sintetizada no Quadro 2 .

\begin{tabular}{|l|l|}
\hline Ano & \multicolumn{1}{|c|}{ Educação Profissional no Brasil } \\
\hline 1909 & $\begin{array}{l}\text { O Decreto-Lei } \text { n }^{\text {O }} 7.566^{2} \text {, de 23 de setembro de 1909, sancionado pelo então } \\
\text { Presidente da República Nilo Peçanha, instituiu oficialmente a educação } \\
\text { profissional brasileira que, vista como instrumento de capacitação ou } \\
\text { adestramento para atender ao crescente desenvolvimento industrial e ao ciclo de } \\
\text { urbanização, tinha caráter assistencialista }{ }^{3} \text { em relação à massa trabalhadora. } \\
\text { Ocorreu a criação de 19 Escolas de Aprendizes Artífices, difundidas com o intuito } \\
\text { de preparar gerações vindouras para a continuidade dos ofícios, suprindo, assim, o } \\
\text { mercado produtivo, dominado pela burguesia emergente, formando profissionais } \\
\text { advindos das camadas pobres da população. } \\
\text { O ensino profissional foi delegado ao Ministério de Indústria e Comércio. }\end{array}$ \\
\hline 1910 & $\begin{array}{l}\text { Foram ofertados cursos de tornearia, mecânica e eletricidade, além das oficinas de } \\
\text { carpintaria e artes decorativas ministradas nas 19 Escolas de Aprendizes Artífices. }\end{array}$ \\
\hline
\end{tabular}




\begin{tabular}{|l|l|}
\hline 1930 & $\begin{array}{l}\text { Ocorreu a instalação de escolas superiores para formação de recursos humanos } \\
\text { necessários ao processo produtivo (início da Industrialização do Brasil). } \\
\text { A partir da década de 1930, o ensino profissional se expandiu no Brasil, incluindo, } \\
\text { em seu público-alvo, ricos e pobres. }\end{array}$ \\
\hline 1937 & $\begin{array}{l}\text { A Constituição de } 1937 \text { fez menção às escolas vocacionais e pré-vocacionais } \\
\text { como dever do Estado, a quem competia, com a colaboração das indústrias e dos } \\
\text { sindicatos econômicos, criar, na esfera de sua especialidade, escolas de } \\
\text { aprendizes, destinadas aos filhos de seus operários e associados. }\end{array}$ \\
\hline 1940 & $\begin{array}{l}\text { Amplitude de atendimento: criação das instituições responsáveis pela formação de } \\
\text { mão-de-obra para os dois principais pilares da economia: a Indústria e o } \\
\text { Comércio. } \\
\text { Surgimento do chamado Sistema S4. }\end{array}$ \\
\hline 1942 & $\begin{array}{l}\text { Criação do SENAI (S pioneiro). } \\
\text { Criação da lei Orgânica da Educação Nacional do Ensino Secundário. }\end{array}$ \\
\hline 1943 & $\begin{array}{l}\text { Criação da Lei Orgânica da Educação Nacional do Ensino Comercial. } \\
\text { Criação do Serviço Nacional de Aprendizagem Comercial (SENAC), do Serviço } \\
\text { Social do Comércio (SESC) e Serviço Social da Indústria (SESI). } \\
\text { Criação da Lei Orgânica da Educação Nacional do Ensino Primário, Normal e } \\
\text { Agrícola. }\end{array}$ \\
\hline $\begin{array}{l}\text { Criação do Serviço Nacional de Aprendizagem Rural (SENAR), do Serviço } \\
\text { Nacional do Transporte (SENAT) } \\
\text { Cooperativismo do Serviço Nacional de Apoio ao } \\
\text { Empresa (SEBRAE). }\end{array}$ \\
\hline 1990 Quadro 2 - Síntese do histórico da educação profissional no Brasil \\
Fonte: Da Autora (2007)
\end{tabular}

Da síntese apresentada no Quadro 2, esclarecemos que a década de 1930 é considerada referencial histórico para a Educação Profissional do Brasil, pois essa década configurou o início da industrialização no país e possibilitou a institucionalização de escolas superiores para formação de recursos humanos necessários ao processo produtivo. Igualmente esclarecemos que, na década de 1940, também foi de suma importância para a educação profissional brasileira, pois, com o surgimento do Sistema S, tomou impulso em amplitude de atendimento.

Atualmente, a formação profissional, no Brasil, ocorre em escolas de Educação Profissional públicas e privadas, sendo que alcança mais sucesso aquela que oferece ao mercado de trabalho trabalhadores que, ao mesmo tempo, conheçam as tecnologias utilizadas pelas empresas, quanto apreendam as novas tecnologias que surgem. Neste contexto, encontramse as escolas de Educação Profissional, com a responsabilidade de gerar saberes coletivos e flexíveis, sintonizados com as novas bases e novas formas de organização produtiva, fundadas na produção e difusão de inovações de cunho tecnológico, marca presente no fechamento do século XX e identidade deste novo século.

\section{ENSINO PROFISSIONAL: REFORMAS E PERSPECTIVAS}

Com o aprimoramento e o surgimento de novas tecnologias, ocorreram expressivas mudanças no setor produtivo nas últimas décadas. $\mathrm{Na}$ área educacional, não poderia ser 
diferente, uma vez que a educação deve ser vanguarda das inovações ou estar em sintonia com elas para dar cabo dos desafios que a modernidade, de modo particular, tem apresentado diariamente. Em face disso, a escolaridade básica realizada em tempo mais prolongado e a proposta de uma Educação Profissional mais abrangente e, que, ultrapasse o adestramento nas técnicas de trabalho, são necessárias, no sentido de nova proposta curricular, em que pese o desenvolvimento de competências profissionais que atendam ao novo perfil produtivo e tecnológico.

A atual Lei de Diretrizes e Bases da Educação Nacional, de 1996, tenta contemplar os desafios expostos, quando afirma o propósito de estender ao poder público a obrigatoriedade de oferta de Ensino Médio, na qualidade de um direito do cidadão. Nos artigos 39 a 42, a educação profissional é concebida como "[...] integrada às diferentes formas de educação, ao trabalho, à ciência e à tecnologia [...]", de modo a conduzir " [...] ao permanente desenvolvimento para a vida produtiva" (BRASIL, 1996, p. 67). No que se refere à organização curricular, a LDB traz diretrizes para que as ofertas educacionais estejam em consonância com a economia mundial.

A elaboração da Lei $n^{\circ}$ 9.394/96 coincide com a ascensão do neoliberalismo e as reformas educacionais, são realizadas sob a orientação e o apoio financeiro de organismos internacionais (BID, BIRD, UNESCO, OIT) (DELUIZ, 2007). Neste sentido, sob a recomendação do Banco Mundial, no Brasil, devem ter prioridade investimento no Ensino Fundamental, podendo haver complementação com cursos de qualificação profissional que sejam de curta duração e tenham baixo custo. Quanto à Educação Profissional, vista como processo longo e dispendioso, o Banco Mundial recomenda que seja repassada, paulatinamente, para a esfera privada (SENAC, 2007).

A reforma educacional, a partir da legislação em vigor, no que se refere à Educação Profissional, dá autonomia para organizar os currículos de suas ofertas de cursos técnicos, desde que tenham como referencial as Diretrizes Curriculares Nacionais, considerando seus respectivos projetos pedagógicos e as peculiaridades regionais (SENAC, 2007).

A legislação da educação em vigor no Brasil, apresenta a proposição de que os currículos sejam pautados pelos perfis profissionais de conclusão, permitindo dessa forma, delimitação de itinerários profissionais, tendo como dispositivos (DEPRESBITERIS, 2001, p. 23):

a) Autonomia escolar;

b) Gestão democrática;

c) Recuperação contínua e os sistemas de avaliação, com polivalência dos aspectos qualitativos sobre os quantitativos;

d) Valorização da docência com o estabelecimento de um plano de carreira para os docentes;

e) Instituição de custo mínimo para a manutenção da qualidade do ensino fundamental;

f) Organização do ensino flexível;

g) Aproveitamento de estudos;

h) Educação continuada;

i) Educação a distância. 
Em relação à Educação Profissional, tratada em capítulo especial, os níveis de ensino com seus respectivos objetivos, são três, a saber: o Básico, o Técnico e o Tecnológico (BRASIL, 1996).

Depresbiteris (2001, p. 25) explica que:

Nível básico - é o nível de educação não-formal e deverá atender, por meio de programas de qualificação, certificação, requalificação.

Nível técnico - é a educação profissional formal. Caminha paralelamente ao

Ensino Médio, uma vez que a obtenção do diploma de técnico está vinculada à conclusão desse nível de ensino.

Nível tecnológico - constitui-se no nível superior da educação profissional.

Além dos três níveis, a Educação Profissional compreende, ainda, os chamados cursos complementares, tais como de especialização, aperfeiçoamento e atualização. Ademais, a organização curricular da Educação Profissional ampara-se na premissa da competência, abordada pelas Diretrizes Curriculares Nacionais da Educação Profissional (DCNs), sempre de forma relacionada à autonomia do trabalhador contemporâneo diante da instabilidade do mundo do trabalho e das mudanças nas relações de produção.

Segundo a Resolução 04/99 da Câmara da Educação Básica do Conselho Nacional da Educação (CNE/CEB), competência é a "[...] capacidade de articular, mobilizar e colocar em ação valores, conhecimentos e habilidades necessários para o desempenho eficiente e eficaz de atividades requeridas pela natureza do trabalho" (BRASIL, 1999b). Para Perrenoud (1999, p. 7), Competência "é a capacidade de agir eficazmente em um determinado tipo de situação, apoiada em conhecimentos, mas sem limitar-se a eles".

Desta forma, a LDB define os parâmetros para a Educação Profissional, tendo como objetivo "desenvolver as aptidões do educando para a vida produtiva" (CONEXÃO SENAI, 2006, p. 82). No que diz respeito à estruturação curricular, além de flexível, é marcada pela prática pedagógica interdisciplinar e contextualizada, pautando-se pelos perfis profissionais. (SENAC, 2007)

Um currículo baseado em competência parte da análise do processo de trabalho. Depresbiteris (2001, p. 53) define o currículo como, "toda a aprendizagem que é planejada e orientada pela escola, quer seja realizada em grupos, quer individualmente, dentro ou fora dela". Neste sentido, se constrói uma matriz referencial a ser transposta pedagogicamente para uma organização modular, adotando-se uma abordagem metodológica baseada em projetos ou resolução de problemas. Para Depresbiteris (2001, p. 59),

Um educador que deseja gerar uma aprendizagem mais significativa é aquele que coloca o educando diante de conflitos cognitivos; é aquele que o incentiva para a solução dos problemas, que coloca em xeque suas soluções para aumentar a sua capacidade de argumentação.

Conforme esclarece Ramos (2007) o foco da estrutura curricular no desenvolvimento de competências centra-se na pedagogia construtivista. Ainda segundo o autor, excluí-se dessa forma a prática pedagógica centrada na transmissão de conteúdos, geralmente dissociados da prática concreta de sujeitos, que por sua vez se situam em uma sociedade complexa e dinâmica. Essa abordagem requer dos profissionais de educação uma nova postura: um maior envolvimento com a comunidade escolar, e assim com os demais atores da educação 
profissional; atenção permanente às tendências do mundo do trabalho. Ramos (2007) comenta que diante desse contexto, impõe-se, também, a necessidade de apropriação de metodologias que favoreçam a aprendizagem significativa.

Para implementação do modelo curricular proposto, recomenda-se a organização dos cursos por módulos, que poderão ter terminalidade permitindo assim, a qualificação profissional técnica e, dessa forma, a certificado de qualificação profissional. Nos casos de módulos sem terminalidade, são emitidas declarações de estudos (SENAC, 2007).

No tocante à certificação, a lei estabelece que ela se dê mediante avaliação de competências, sob as chancelas:

a) Declaração de Estudos para aqueles que concluírem módulos sem terminalidade;

b) Certificado de Qualificação Básica, para o nível básico da Educação Profissional;

c) Certificado de Qualificação Profissional Técnica para quem concluir módulos com terminalidade ou correspondentes a de auxiliares técnicos existentes no mercado; e

d) Diploma de Técnico, para aqueles que tenham concluído o nível médio de ensino (SENAC, 2007).

Já difundida na Europa, Estados Unidos e América Latina (Chile, México e Argentina), a certificação começa a ser implementada no_Brasil, no contexto do Programa Brasileiro de Qualidade e Produtividade (PBQP), por meio da criação de um Sistema Brasileiro de Certificação, cujas normas objetivam avaliar a conformidade de produtos, serviços, sistemas e pessoal.

Apesar de compor as tendências globalizantes de normas e padrões culturais e políticos, transposições desagregadas de certas teorias para a realidade brasileira causam sérias consequiências: no âmbito das relações de trabalho, o enfraquecimento do conceito de qualificação pela competência pode levar à desfiliação dos trabalhadores do frágil sistema de regulações sociais deste país; no âmbito educacional, as apropriações apressadas e limitadas desta noção podem reduzir a educação profissional a práticas voltadas para formações restritas, num triste recuo a princípios educacionais considerados superados pelo debate educacional crítico das últimas décadas (RAMOS, 2007).

No Brasil, as reformulações teóricas e sócio-empíricas referidas a essas tendências incidem mais fortemente na política da educação profissional a partir dos anos de 1990 e tomam corpo jurídico-institucional no governo de Fernando Henrique Cardoso.

A Política de Educação Profissional do MEC objetiva “[...] promover a transição entre a escola e o mundo do trabalho, capacitando jovens e adultos com conhecimentos e habilidades gerais e específicas para o exercício de atividades produtivas" (BRASIL 1997, p. 34).

Apesar de entender 'a educação profissional, integrada às diferentes formas de educação, ao trabalho, à ciência e à tecnologia, com o objetivo de garantir ao cidadão o direito ao permanente desenvolvimento de aptidões para a vida produtiva e social', o foco da educação profissional são as novas exigências do 
mundo do trabalho, explicitadas de acordo com as áreas profissionais e os perfis de competências estabelecidos nas Diretrizes Curriculares Nacionais da Educação Profissional de Nível Técnico. As 'aptidões para a vida social' ou a preocupação com a formação ampliada dos sujeitos, que inclui a dimensão sociopolítica, não são detalhadas e especificadas na legislação educacional (DELUIZ, 2001).

Segundo o Parecer no 16/99 do CNE, a Educação Profissional norteia-se pelos princípios da igualdade de condições para o acesso e a permanência na escola, bem como pelos princípios que regem a LDB, sobretudo pelo Artigo 3, que preceitua sobre a educação em geral (BRASIL, 1999). O mesmo parecer igualmente ressalta os valores estéticos, políticos e éticos como norteadores da Educação Profissional. Contudo, alerta que esses valores só se concretizarão por meio de uma pedagogia focada "na atividade do aluno, na sua aprendizagem para um fazer com arte - o fazer bem feito" (BRASIL, 1999). Isto supõe que seja promovido o desenvolvimento da criatividade, da iniciativa e da liberdade de expressão; que seja dada atenção especial à elaboração de currículos e à adoção de práticas didáticas que assegurem a todos a constituição de competências laborais importantes para o exercício da subsistência com dignidade, com auto-respeito e reconhecimento social como seres produtivos; seja reconhecido e valorizado o ethos de cada profissão, com base na solidariedade e na responsabilidade, visando ao exercício da vida produtiva e da cidadania (SENAC, 2007).

Os aspectos inovadores a serem considerados, na atual legislação da educação nacional, dizem respeito, à abertura a inovações: democrática, pluralista, descentralizadora, desburocratizadora, flexível e que facilite a inovação (CONEXÃO SENAI, 2006, p.81). O capítulo específico para a Educação Profissional alerta para a necessidade de uma pedagogia que desenvolva as aptidões do educando e para o direito de todos ao acesso a esta modalidade de ensino. Inclusive se torna concreta a lógica inerente à reforma propugnada pelos organismos oficiais, no que se refere à melhor qualificação do trabalhador e à sua valorização social por meio do Ensino por Competências (SENAC, 2007).

\section{CONSIDERAÇÕES FINAIS}

Os seres humanos com sua cognição e tecnologia, ao longo da história, conseguiram produzir soluções para enfrentar os desafios impostos no seu dia a dia, bem como nas suas relações e interferências com os demais componentes ambientais.

A partir da disseminação das escolas de Artes e Ofícios, as técnicas passaram a ser sistematicamente difundidas com o intuito de preparar gerações para a continuidade dos ofícios.

Com o aprimoramento e o surgimento de novas tecnologias, ocorreram expressivas mudanças no setor produtivo. Na área educacional, as inovações estão em sintonia para dar conta dos desafios que a modernidade, de modo particular, tem apresentado diariamente.

Já a legislação em vigor no Brasil, atribui às agências de educação profissional autonomia para organizar currículos e a oferta de cursos técnicos, desde que, seja devidamente referenciada, as Diretrizes Curriculares Nacionais. 
Neste sentido, a Educação Profissional centra-se em um currículo baseado nas competências, com metodologias voltadas para projetos ou resolução de problemas.

\section{REFERÊNCIAS}

BRASIL. Decreto-Lei 7.566. Disponível em: $<\underline{w w w . p l a n a l t o . g o v . b r}>$. Acesso em: 10 maio 2007.

Decreto-Lei $n^{\circ}$ 4.048, de 22 de janeiro de 1942. Cria o Serviço Nacional de Aprendizagem dos Industriários. Disponível em: $<\underline{\text { www.planalto.gov.br }}>$. Acesso em: 10 maio 2007.

Lei Federal $n^{\circ}$ 9.394, de 20 de dezembro de 1996. Estabelece as diretrizes e base da educação nacional - LDB. Disponível em: <www.planalto.gov.br>. Acesso em: 10 maio 2007.

Parecer 16/99, de 05 de outubro de 1999. Documento, Brasília, n. 457, p. 3-73, out. 1999. Fixa as Diretrizes Curriculares Nacionais para a Educação_Profissional de Nível Técnico. 1999a. Disponível em: <www.planalto.gov.br>. Acesso em: 10 maio 2007.

Resolução CNE/CEB n ${ }^{\circ}$ 04/99, de 5 de outubro de 1999. Institui as Diretrizes Curriculares Nacionais para a Educação Profissional do Nível Técnico. 1999 b.

DELUIZ, Neise. O Modelo das competências profissionais no mundo do trabalho e na educação: implicação para o currículo. Boletim Técnico do SENAC, Rio de Janeiro, v. 27, n. 3, set./dez. 2001. Disponível em: < http://www.senac.br/BTS/273/boltec273b.htm>. Acesso em: 10 maio 2007.

DEPRESBITERIS, Lea. Concepções atuais de educação profissional. 3 ed. Brasília: SENAI/DN, 2001.

ENCICLOPÉDIA DE DIDEROT E D’ALEMBERT. Disponível em:< www.educ.fc.ul.pt/hyper/enciclopedia/cap2p4/secour.htm> Acesso em: 15 ago. 2006.

FREIRE, Paulo. Pedagogia da autonomia: saberes necessários á prática educativa. 33. ed. São Paulo: Paz e Terra, 2006.

FRIGOTTO, Gaudêncio. Modelos ou modos de produção e educação: dos conflitos às soluções. Tecnologia educacional. Rio de Janeiro, v. 27, n. 147, p. 7-14, out./dez. 1999.

MANACORDA, M. A. História da educação: da Antigüidade aos nossos dias. 4. ed. São Paulo: Cortez, 1995.

MANFREDI, Sílvia Maria. Educação profissional no Brasil. São Paulo: Cortez, 2002. 
MÉSZÁROS, Istvan. A educação para além do capital. Trad. Isa Tavares. São Paulo: Bomtempo, 2005.

PERRENOUD, Philippi. Construir competências desde a escola. Porto Alegre: Artes Médicas, 1999.

RAMOS, Marise Nogueira. A educação profissional no contexto da educação nacional. Disponível em: <http: // www. Educacaoonline. pro. Br/ reforma_da_educacao profissional.asp?f_id_artigo=298>. Acesso em: 10 maio 2007.

SENAC. A educação profissional no contexto da educação. Disponível em: <www.senac.br/conheca/referenciais/ref2.htm>. Acesso em: 9 maio 2007.

\footnotetext{
${ }^{1}$ Expressão que define ações e atitudes, criação de instrumentos e artefatos para atividades do homem sobre a natureza, sua sobrevivência, subsistência, ataque ou defesa; arte ou registro de sua presença nos ambientes terrestres, a partir de elementos e materiais coletados no meio em que os humanos se encontravam (MANFREDI, 2002).

${ }^{2}$ Segundo o Decreto-Lei 7.566, de 1909, era necessário não só capacitar os filhos dos desfavorecidos da fortuna com indispensável preparo técnico intelectual, como também fazer com que adquirissem hábitos de trabalho profícuo, o que os afastaria da ociosidade, escola do vício e do crime, sendo esse um dos deveres do Governo, com vistas a formar cidadãos úteis à Nação (BRASIL, 1909).

3 Segundo o parecer $16 / 99$, do CNE, a educação profissional deveria "amparar as crianças órfãs e abandonadas", diminuir "a criminalidade e a vagabundagem" e favorecer "os órfãos e desvalidos da sorte" (BRASIL, 1999).

${ }^{4}$ As escolas do Sistema S são financiadas e geridas pelos empresários por via de recolhimento de $1 \%$ sobre a folha de salários e fiscalizadas pelo Poder Público. Representantes dos governos federais e estaduais fazem parte de todos os conselhos deliberativos, e o Tribunal de Contas da União examina a aplicação dos recursos de todo o Sistema S. O modelo do Sistema S espalhou-se rapidamente por toda a América Latina.

${ }^{5}$ Desmembrado do SENAI para dar conta da mão-de-obra do setor de transportes terrestres.
}

Originais recebidos em: 11 fev. 2008.

Texto aprovado em: 28 fev. 2008.

\section{SOBRE A AUTORA}

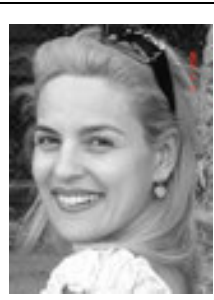

Lidiane Soares Wittaczik
Mestre em Educação pela Universidade Regional de Blumenau (PPGE-FURB), tendo concluído o mestrado em fevereiro de 2008. Ela adquiriu o grau de Especialista em Interdisciplinaridade pelo Instituto Brasileiro de Pós-Graduação (IBPEX) em 2002. Licenciatura em Pedagogia no Centro Universitário de Jaraguá do Sul (UNERJ) no princípio do ano de 2000. Sua área de pesquisa processos e métodos didático-pedagógicas, onde teve como tema Ensino por Competência: A conceção dos Professores do SENAI/SC de Jaraguá do Sul. Lidiane fez seu estágio docente na FURB, com a disciplina de Educação Inclusiva e atualmente exerce a função de coordenadora pedagógica dos cursos Técnicos e de Tecnologia do SENAI de Jaraguá do Sul.

E-mail: lidiane@senai-sc.ind.br 